\title{
Impact of Family Function and Psychosocial Factors on Development of Anxiety and Depression in First-Year Medical Students
}

\author{
Delila Lisica ${ }^{1}$, Elma Ramakic ${ }^{2}$, Amela Dzubur-Alic ${ }^{3}$ \\ 1, 3 Department of Public Health, University of Sarajevo, Bosnia and Herzegovina. \\ ${ }^{2}$ Medical Faculty, University of Sarajevo, Bosnia and Herzegovina.
}

\section{ABSTRACT}

\section{BACKGROUND}

In the first year of studies, students face many changes. On one side is the demanding medical education, and on the other side, is to find a balance with old friends, parents, and a new social environment. These changes may result in psychological symptoms such as anxiety or depression, which is the most commonly, reported mental disorder among students. This study intended to explore the presence of anxiety and depression symptoms in first-year medical students and investigate how family cohesion, flexibility and psychosocial factors influence anxiety and depression.

\section{METHODS}

149 medical students (76.5 \% females and $23.5 \%$ males) took part in a crosssectional study. The survey was conducted via the sociodemographic questionnaire, Multidimensional Scale of Perceived Social Support, Rosenberg Self-esteem Scale, the short version of Loneliness Scale, Family Adaptability \& Cohesion Scale, Beck Anxiety Inventory, and Beck Depression Inventory.

\section{RESULTS}

The prevalence of moderate and severe anxiety and depression symptoms among medical students was $53.8 \%$ and $19.5 \%$, respectively. Female students experienced higher levels of anxiety and depression compared to their male colleagues. Students who had physical activities at least once a week showed significantly lower anxiety and depression scores. Anxiety and depression were positively associated with loneliness and negatively associated with perceived social support from family and self-esteem. Depression was also negatively associated with family cohesion and adaptability. Moreover, the results revealed that family cohesion was a strong predictor of the severity of depression symptoms.

\section{CONCLUSIONS}

This study shows that variables such as gender, physical activities,

feeling of loneliness, low self-esteem, and perceived social support from family play an important role in the experience of anxiety and depression among medical students. This study raises awareness about mental disorders in medical students, especially anxiety and depression, and invites the placement of these problems among the top priorities of public health policies.

\section{KEY WORDS}

Anxiety; Depression, Family Relations, Students
Corresponding Author:

Delila Lisica,

Medical Faculty,

Department of Public Health,

University of Sarajevo-71000,

Bosnia and Herzegovina.

E-mail: delila.lisica@gmail.com

DOI: $10.14260 / j e m d s / 2021 / 758$

How to Cite This Article:

Lisica D, Ramakic E, Dzubur-Alic A. Impact of family function and psychosocial factors on development of anxiety and depression in first-year medical students. J Evolution Med Dent Sci 2021;10(44):3747-3751, DOI: 10.14260/jemds/2021/758

Submission 21-09-2021,

Peer Review 30-10-2021,

Acceptance 06-11-2021,

Published 30-11-2021.

Copyright (c) 2021 Delila Lisica et al. This is an open access article distributed under Creative Commons Attribution License [Attribution 4.0 International (CC BY 4.0)] 


\section{BACKGROUND}

Anxiety is the most prevalent mental disorder and affects one-third of the population during their lifetime. ${ }^{1}$ Together with depression they are the most reported mental disorders in the student population. ${ }^{2}$ According to previous studies medical students often faced with symptoms of depression and anxiety. ${ }^{3,4}$

They can cause different problems, one of the most concerning being suicidal intentions. According to a metaanalysis among health science students, $22.0 \%$ of students had suicidal intention, compared to $18.0 \%$ recorded for the general university population. ${ }^{3}$

The transitional period that occurs from adolescence to adult age and changes related to the changing environment, friends, and the role of graduating from high school to university can all be difficult for students. ${ }^{5}$

This period is often characterized by the risk of loneliness, ${ }^{6}$ which is not necessarily associated with social isolation. It can be present even though peers surround students, so according to research, students may have high levels of social contact but still feel lonely due to cognitive differences between desired relationship quality and actual experiences. ${ }^{7}$

A deficit in social support is also related to many psychological problems such as anxiety and depression.8,9 According to research that was done on medical students from China, social support and family functioning highly correlated with anxiety and depression symptoms. ${ }^{9}$ Lack of parental support can be detrimental, as parental support is more consistent than peer support. ${ }^{8}$

The association of family with the onset of depressive symptoms could be assessed by parental psychopathology or familial instability. ${ }^{8}$ Family functionality includes family cohesion which is defined as the emotional bonds between family members and the quality of family adaptability to the organization, rules within the family, roles, and family's leadership. ${ }^{10}$

The ability of a family to be flexible, to be able to reorganize in moments of new challenges are important since rigidity in family dynamics can stifle creative thinking, create feelings of helplessness and frustration in family system members. ${ }^{11}$

The interrelationship of family functioning, cohesion, and adaptability may be a protective factor against the development or maintenance of symptoms of anxiety and depression. ${ }^{12}$

According to the previous research, anxiety and depression may have a negative effect on social adjustment.13 There are a few factors that could help students to adjust better to university life, one of those is having a good relationship with parents and having a feeling of receiving social support. 13

Social support and high self-esteem can reduce the negative impact of stress and transition and be a protective factor for mental disorders. ${ }^{14,15}$

This study intended to explore the presence of anxiety and depression symptoms in first-year medical students and investigate how family cohesion, flexibility and psychosocial factors influence anxiety and depression.

\section{METHODS}

A cross-sectional study was conducted at the beginning of January 2020 that enrolled 149 students (76.5\% females and $23.5 \%$ males). All students were in their first year of education at the Medical Faculty University of Sarajevo. A structured questionnaire link using 'Google form' was sent to students through E-mail. Participation was voluntary and participants provided full consent before participating in the online survey. Completing the questionnaires was after the lectures and took about 15 minutes. The study was approved by the ethics committee of the Medical Faculty, University of Sarajevo, Bosnia and Herzegovina.

The survey was conducted via the Sociodemographic Questionnaire, Multidimensional Scale of Perceived Social Support, Rosenberg Self-Esteem Scale, the short version of Loneliness Scale, Family Adaptability \& Cohesion Scale, Beck Anxiety Inventory, and Beck Depression Inventory.

The Sociodemographic Questionnaire consists of basic information such as gender, whether he/she currently uses cigarettes, alcohol, and has physical activities.

Multidimensional Scale of Perceived Social Support - The MSPSS is a brief 12-item, self-administered measurement tool with three subscales: Family (SS-Fa), Friends (SS-Fr), and Significant Others (SS-0). Each item uses a seven-point Likert scale ranging from 1 (very strongly disagree) to 7 (very strongly agree). A higher score indicates greater social support perceived by an individual. ${ }^{16}$

The Rosenberg Self-Esteem Scale (RSS) is a 10-item scale that measures global self-worth by measuring both positive and negative feelings about the self. The scale is believed to be unidimensional. All items are answered using a 4-point Likert scale format ranging from strongly agree to strongly disagree. ${ }^{17}$

A short version of the Loneliness Scale (ULS) contains 7 particles relevant to loneliness. Responses are also recorded on a Likert-type scale from 1 to 5 , while the total result forms as a sum of results in all the particles. The scale is a one-factor structure. 18

Family Adaptability (FA) \& Cohesion Scale (FC) is designed to measure family cohesion (the degree to which family members are separated or connected to their family) and family adaptability (the extent to which the family system is flexible and able to change).

The instrument consists of 20 statements and is easy to administer and score. The participant is asked to read each statement and decide on a scale from 1 (almost never) to 5 (almost always) how often the statement occurs. ${ }^{19}$

The Beck Anxiety Inventory (BAI) is a 21-item questionnaire to measure the severity of anxiety symptoms. Each item allows the patient four choices, from no symptoms to severe symptoms. For each item, the patient is asked to report how he or she has felt during the past week. The items are scored as $0,1,2$, or 3 . The score range is $0-63$. A total score of 0-7 is considered a minimal range, 8-15 is mild, 1625 is moderate, and 26-63 is severe. ${ }^{20,21}$

Beck Depression Inventory (BDI) is a 21-item questionnaire to measure depression symptoms. The 21 symptoms and attitudes contained in the BDI reflect the intensity of the depression; items receive a rating of zero to three to reflect their intensity and are summed linearly to create a score that ranges from 0 to 63 . The centre for 
cognitive therapy has set the following guidelines for BDI cutoff scores to be used with affective disorder patients: scores from 0 to 9 indicate no or minimal depression; scores from 10 to 18 indicate mild to moderate depression; scores from 19 to 29 indicate moderate to severe depression, and scores from 30 to 63 indicate severe depression. ${ }^{22}$

\section{Statistical Analysis}

The collected data were analysed using descriptive and inferential statistics via the SPSS software version 21 (IBM Inc., Armonk, NY, USA). The collected data were analysed by parametric procedures and non-parametric procedures. Results were obtained by descriptive statistics, linear regression, independent sample test, and Spearman's correlation coefficient (r). Means (percentages) and frequencies were reported for quantitative and qualitative variables, respectively. The significance level for all statistical tests was set at $\mathrm{P}<0.05$.

\section{RESULTS}

According to the results, $24.16 \%$ of medical students were faced with moderate and $39.6 \%$ of students with high levels of anxiety. That is, the prevalence of moderate and severe anxiety among medical students was $53.8 \%$. On the other hand, $14.09 \%$ of students faced moderate symptoms of depression and $5.37 \%$ with severe symptoms of depression, i.e. the prevalence of moderate and severe depression symptoms among medical students was $19.5 \%$.

Sociodemographic variables and differences between participants in the experience of anxiety and depression symptoms showed, that there were no statistically significant differences between students who consumed nicotine (BAI: $t$ $=.325 ; \mathrm{P}=.390$; BDI: $\mathrm{t}=.148 ; \mathrm{P}=.090$ ) or alcohol (BAI: $\mathrm{t}=$ 0.086; $\mathrm{P}=.541 ; \mathrm{BDI}: \mathrm{t}=1.902 ; \mathrm{P}=.897)$. Significant differences in experience anxiety symptoms $(\mathrm{t}=0.182 ; \mathrm{P}<$ $.001)$ but also depression $(\mathrm{t}=7.504 ; \mathrm{P}<.01)$ were found between genders. The results showed that there were statistically significant differences between students who had physical activity, at least once a week in the experience of anxiety symptoms $(\mathrm{t}=7,885 ; \mathrm{P}<0.01)$ but also depression $(\mathrm{t}$ $=3,138 ; \mathrm{P}<.05$ ).

\begin{tabular}{|c|c|c|c|c|c|c|c|c|c|c|}
\hline & SS-O & SS-Fa & SS-Fr & SS-T & UCLA & RSS & $\mathrm{COH}$ & ADA & ANX & D \\
\hline SS-O & 1 & $.378^{\dagger}$ & $.517^{\dagger}$ & $.768^{\dagger}$ & $-.436^{\dagger}$ & $.236^{+}$ & $.333^{\dagger}$ & $.234^{\dagger}$ & -.013 & -159 \\
\hline SS-Fa & & 1 & $.203^{*}$ & $.609^{+}$ & $-.335^{\dagger}$ & $.281^{+}$ & $.633^{+}$ & $.470^{+}$ & $-.177^{*}$ & $-.376^{+}$ \\
\hline SS-Fr & & & 1 & $.809^{+}$ & $-.527^{\dagger}$ & $.259^{\dagger}$ & .139 & $.163^{*}$ & -.064 & -.140 \\
\hline SS-T & & & & 1 & $-.600^{\dagger}$ & $.343^{\dagger}$ & .459† & $.363^{\dagger}$ & -.106 & $-299+$ \\
\hline UCLA & & & & & 1 & $-.530^{+}$ & $-.334^{\dagger}$ & $-.253^{+}$ & $.322^{+}$ & $.445^{\dagger}$ \\
\hline RSS & & & & & & 1 & $.358^{+}$ & .178 & $-.468^{\dagger}$ & $-.676^{+}$ \\
\hline $\mathrm{COH}$ & & & & & & & 1 & $.705^{+}$ & -.047 & $-.375^{\dagger}$ \\
\hline ADA & & & & & & & & 1 & -.018 & $-.164^{*}$ \\
\hline ANX & & & & & & & & & 1 & $.724^{\dagger}$ \\
\hline D & & & & & & & & & & 1 \\
\hline \multicolumn{11}{|c|}{$\begin{array}{l}\text { Table 1. Correlations between Subscale of Social Support, Loneliness, } \\
\text { Self-Esteem, Family Cohesion, Family Adaptability, Anxiety and } \\
\text { Depression Symptoms. }\end{array}$} \\
\hline
\end{tabular}

Correlation analysis indicated a negative significant relationship between reported anxiety symptoms and perceived social support from family $(r=-.177 ; \mathrm{P}<.05)$ and self-esteem $(\mathrm{r}=-.468 ; \mathrm{P}<.01)$. As presented anxiety was positively correlated with loneliness $(\mathrm{r}=.322 ; \mathrm{P}<.01)$.
According to the results, anxiety had the highest correlation with self-esteem ( $\mathrm{r}=-.468 ; \mathrm{P}<.01)$.

Depression symptoms were statistically negatively correlated with perceived social support from family $(\mathrm{r}=$ .376; $\mathrm{P}<.01$ ), self-esteem ( $\mathrm{r}=-.676$; $\mathrm{P}<.01)$, family cohesion $(\mathrm{r}=-.375 ; \mathrm{P}<.01)$, and adaptability. As the results showed in Table 1, depression was positively correlated with loneliness $(\mathrm{r}=.445 ; \mathrm{P}<.01)$. Depression has the highest correlation with self-esteem $(\mathrm{r}=-.676 ; \mathrm{P}<.01)$. According to the results there was also high positive correlation between anxiety and depression $(\mathrm{r}=.724 ; \mathrm{P}<.01)$.

\begin{tabular}{|c|c|c|c|c|c|c|c|c|}
\hline & & SD $\beta$ & $\mathbf{p}$ & $\mathbf{R}$ & $\mathbf{R}^{2}$ & $\Delta \mathbf{R}$ & $\mathbf{F}$ & p \\
\hline Anxiety & $\begin{array}{l}\text { Cohesion } \\
\text { Adaptability }\end{array}$ & $\begin{array}{l}-.049 \\
.016\end{array}$ & $\begin{array}{l}.690 \\
.894\end{array}$ & .038 & .001 & -.012 & .108 & .898 \\
\hline Depression & $\begin{array}{l}\text { Cohesion } \\
\text { Adaptability }\end{array}$ & $\begin{array}{l}. .505 \\
.195\end{array}$ & $\begin{array}{l}.000 \\
.086\end{array}$ & .385 & .148 & .136 & 12.695 & .000 \\
\hline
\end{tabular}

According to the results in Table 2, family cohesion and adaptability were not significant predictors in the explanation of anxiety. On the other side, the results showed that the final model of regression analysis for depression was statistically significant. Family cohesion was a statistically significant predictor in the explanation of depression $(\beta=$ $.505 ; \mathrm{P}<.000)$. As the results showed adaptability and family cohesion explained $14.8 \%(\Delta \mathrm{R}=13.6)$ of the cases of depression.

\section{DISCUSSION}

The prevalence of moderate and severe anxiety and depression symptoms among medical students was $53.8 \%$ and $19.5 \%$, respectively. Female students experienced higher levels of anxiety and depression compared to their male colleagues. Students who practiced physical activities at least once a week showed significantly lower anxiety and depression scores. Anxiety and depression were positively associated with loneliness and negatively associated with perceived social support from family and self-esteem. Depression was also negatively associated with family cohesion and adaptability. Moreover, the results of regression analysis revealed that family cohesion was a strong predictor of the severity of depression symptoms.

During the study of medicine, the entire educational program is focused on understanding and solving problems that patients could have, and how we can help patients. However, students very rarely encounter subjects that are focused on recognizing their stress, anxiety, dissatisfaction, ways of coping with stress, and strengthening their capacities. Not only learning about healthy habits, but also the possibilities of applying them in daily life.

According to the results, all students who reported moderate and severe symptoms of depression also reported moderate and severe symptoms of anxiety. The correlation of anxiety and depression in our study was high which is in line with Stöber \& Joormann (2001) that anxiety and depression highly correlate at the symptom level. ${ }^{23}$

According to the systematic review, health sciences students reported higher levels of anxiety and depression compared to the general population of students. Among the health science students, $43.6 \%$ had anxiety symptoms, 
compared to $17.0 \%$ recorded for the general university population, and $33.1 \%$ had depressive symptoms, compared to $23.4 \%$ of the general university population. ${ }^{3}$ In another study where researchers examined the prevalence of anxiety and depression in medical and pharmacy students, $36.6 \%$ of student's experienced moderate or severe symptoms of anxiety, or $34.1 \%$ symptoms of depression. ${ }^{4}$

The results of previous research conducted on medical and pharmacy students showed similarity in reports of higher levels of anxiety and depression in female students, in contrast to male colleagues. ${ }^{4}$ In our study, there was also a statistically significant difference between male and female students in the experience of anxiety symptoms and depression symptoms. It can be explained by the fact that women notice and report symptoms before, also one of the reasons could be that men have more business opportunities in Western countries. ${ }^{4}$ The obtained results also speak in favour of physical activity which is significantly lessening the experience of anxiety and depression symptoms. That is students who engaged in physical activities at least once a week reported minor ailments caused by symptoms of anxiety and/or depression. Although previous research that had dealt in more detail with the relationship and impact of physical activity suggests that more intense physical activities are associated with better mental health, i.e. fewer symptoms of anxiety and depression, but not low levels of physical activity. ${ }^{24} \mathrm{~A}$ possible explanation for this discrepancy may be that students who devoted at least once a week for several hours to physical activities were in contact with other people in a different way than attending lectures. They also felt less lonely and had a better picture of themselves. Engaging in physical activities even once a week was enough for first-year medical students to produce physiological responses that had a positive effect.

In our study, anxiety and depression were positively associated with loneliness and negatively associated with self-esteem. The obtained results are in line with previous research, i.e. low self-esteem is associated with anxiety, ${ }^{14,25}$ and depression, ${ }^{25}$ while on the other hand, high self-esteem played a protective role. ${ }^{14}$

In the study by Richardson, Elliott \& Roberts (2017), were the longitudinal links between loneliness and mental health in university students. ${ }^{6}$ According to the results obtained, there is an association between loneliness and general mental health, anxiety, and depression. In the beginning, greater isolation predicted increased levels of depression and anxiety, i.e. worse global mental health. Suggesting that loneliness exacerbates existing problems with mental health or leads to direct deterioration in mental health through time. Loneliness is positively increased with depression, i.e. higher levels of loneliness are associated with higher levels of depression symptoms. During the transition period, students are facing many changes, one of which is the possibility of separation from previous social support. The importance of maintaining or providing new support during the transition can reduce feelings of loneliness and symptoms of depression.

In our study, there was a negative association between perceived support of the family, family cohesion, and adaptability with symptoms of anxiety and depression. The results suggested that the symptoms of anxiety and depression were more pronounced in students who did not perceive support from family members, who could not express their own emotions and in family environments where there is a lack of flexibility in family dynamics.

According to research conducted on a group of medical students in China, social support and family functionality have played an important role in reducing stress perceptions, coping with stress, and improving mental well-being. Symptoms of depression and anxiety were negatively associated with family functioning and social support. ${ }^{9}$

The family environment can influence the development of depression symptoms that determine a person and his or her belief in the acceptance and expression of emotions and the manner of coping in overwhelming situations. ${ }^{26}$

Lack of social support increases the risk of depression symptoms. Parental support, i.e. the perception of lack of parental support is more strongly related to depression compared to the perception of support by peers. ${ }^{8}$ Parental support is consistent concerning the support of peers, and parents can provide better support, considering that advice can rely on more life experience.

Positive interaction patterns of the family environment can facilitate coping with situations that are triggers of emotional sufferings which are associated with stressors and demands. $^{12}$ The higher levels of perceived cohesion and flexibility in family systems are facilitating positive communication which affects the reduction of anxiety and depression. Family functioning may also affect the processes that alleviate symptoms. ${ }^{12}$

In our study, the results revealed that family cohesion was a strong predictor of the severity of depression symptoms. According to previous research, family factors influence the development and maintenance of depression in young adults. ${ }^{27}$ Depression symptoms in young adults are associated with poor family cohesion. ${ }^{27}$ The family environment is a major factor in the prevalence of depression symptoms in Chinese students. ${ }^{28}$ Severe symptoms of depression were reported by students who had higher levels of family conflict and control or low family cohesion. Families with low cohesion are the families with a lack of communication, and the inability to express opinions about emotions. The results obtained suggest the importance of emotions and association with family members, and how low levels of cohesion within the family system are a strong predictor of depressive symptoms.

It is also important to mention that adequate levels of cohesion within the family system can help and encourage members to seek help at times when it is needed. Dysfunctional families may have the opposite attitude out of fear of stigma or shame if a family member seeks help. ${ }^{29}$

\section{CONCLUSIONS}

This study shows that variables such as gender, physical activities, and feelings of loneliness, low self-esteem, and perceived social support from family play an important role in the experience of anxiety and depression among medical students. Family environment, especially cohesion, is a strong predictor of depression symptoms. This study raises awareness about mental disorders in medical students, especially anxiety and depression, and invites the placement 
of these problems among the top priorities of public health policies.

Data sharing statement provided by the authors is available with the full text of this article at jemds.com.

Financial or other competing interests: None.

Disclosure forms provided by the authors are available with the full text of this article at jemds.com.

\section{REFERENCES}

[1] Bandelow B, Michaelis S. Epidemiology of anxiety disorders in the 21st century. Dialogues Clin Neurosci 2015;17(3):327.

[2] Auerbach RP, Mortier P, Bruffaerts R, et al. WHO World Mental Health Surveys International College Student Project: Prevalence and distribution of mental disorders. J Abnorm Psychol 2018;127(7):623-38.

[3] de Paula W, Breguez GS, Machado EL, et al. Prevalence of anxiety, depression, and suicidal ideation symptoms among university students: a systematic review. Braz J Health Rev 2020;3(4):8739-56.

[4] Ibrahim MB, Abdelreheem MH. Prevalence of anxiety and depression among medical and pharmaceutical students in Alexandria University. Alexandria J Med 2015;51(2):167-73.

[5] MacKean G. Mental health and well-being in postsecondary education settings. In CACUSS pre-conference workshop on mental health 2011.

[6] Richardson T, Elliott P, Roberts R. Relationship between loneliness and mental health in students. J Public Ment Health 2017;16(2):48-54.

[7] Diehl K, Jansen C, Ishchanova K, et al. Loneliness at universities: determinants of emotional and social loneliness among students. Int J Environ Res Public Health 2018;15(9):1865.

[8] Stice E, Ragan J, Randall P. Prospective relations between social support and depression: differential direction of effects for parent and peer support? J Abnorm Psychol 2004;113(1):155-9.

[9] Shao R, He P, Ling B, et al. Prevalence of depression and anxiety and correlations between depression, anxiety, family functioning, social support and coping styles among Chinese medical students. BMC Psychol 2020;8(1):38.

[10] García-Huidobro D, Puschel K, Soto G. Family functioning style and health: opportunities for health prevention in primary care. Br J Gen Pract 2012;62(596):e198-203.

[11] Baker JK, Seltzer MM, Greenberg JS. Longitudinal effects of adaptability on behavior problems and maternal depression in families of adolescents with autism. J Fam Psychol 2011;25(4):601-9.

[12] Berryhill MB, Harless C, Kean P. College student cohesive-flexible family functioning and mental health: examining gender differences and the mediation effects of positive family communication and self-compassion. Fam J 2018;26(4):422-32.

[13] Wohn DY, LaRose R. Effects of loneliness and differential usage of Facebook on college adjustment of first-year students. Computers \& Education 2014;76:158-67.
[14] Millings A, Buck R, Montgomery A, et al. School connectedness, peer attachment, and self-esteem as predictors of adolescent depression. J Adolesc 2012;35(4):1061-7.

[15] Glozah FN. Effects of academic stress and perceived social support on the psychological wellbeing of adolescents in Ghana. Open J Med Psychol 2013;2(4):143-50.

[16] Zimet GD, Dahlem NW, Zimet SG, et al. The multidimensional scale of perceived social support. Journal of Personality Assessment 1988;52(1):30-41.

[17] Rosenberg, M. Society and the adolescent self-image. Princeton, NJ: Princeton University Press 1965.

[18] Lacković-Grgin K, Penezić Z, Nekić M. Kratka verzija UCLA skale usamljenosti. U: Lacković-Grgin K, Proroković A, Ćubela V, Penezić Z (ur). Zbirka Psihologijskih skala i upitnika, Zadar: Filozofski fakultet, 2002:77-78. [in english: Short version of the Lonliness Scale]

[19] Olson DH, Portner J, Lavee Y. Family adaptability and cohesion evaluation scales (FACES-III) 1986.

[20] Beck AT, Epstein N, Brown G, et al. An inventory for measuring clinical anxiety: psychometric properties. J Consult Clin Psychol 1988;56(6):893-7.

[21] Beck AT, Steer RA. Manual for the revised Beck Anxiety Inventory. San Antonio, TX: Psychological Corporation 1990.

[22] Beck AT, Steer RA. Manual for the revised Beck Depression Inventory. San Antonio, TX: Psychological Corporation 1987

[23] Stöber J, Joormann J. Worry, procrastination, and perfectionism: differentiating amount of worry, pathological worry, anxiety, and depression. Cognitive Therapy and Research 2001;25(1):49-60.

[24] Doré I, O'Loughlin JL, Beauchamp G, et al. Volume and social context of physical activity in association with mental health, anxiety and depression among youth. Prev Med 2016;91:344-50.

[25] Ratanasiripong P, China T, Toyama S. Mental health and well-being of university students in Okinawa. Educ Res Int 2018;2018:1-7.

[26] Freed RD, Rubenstein LM, Daryanani I, et al. The relationship between family functioning and adolescent depressive symptoms: the role of emotional clarity. J Youth Adolesc 2016;45(3):505-19.

[27] Sander JB, McCarty CA. Youth depression in the family context: familial risk factors and models of treatment. Clin Child Family Psychol Rev 2005;8(3):203-19.

[28] Yu Y, Yang X, Yang Y, et al. The role of family environment in depressive symptoms among university students: a large sample survey in China. PloS One 2015;10(12):e0143612.

[29] Ta VM, Holck P, Gee GC. Generational status and family cohesion effects on the receipt of mental health services among Asian Americans: Findings from the national Latino and Asian American study. Am J Public Health 2010;100(1):115-21. 